\title{
Configurações
}

Revista de sociologia

$24 \mid 2019$

Imaginar "futuros" do trabalho, contextos e vivências subjetivas

\section{Alice Goffman (2014), "On The Run: Fugitive Life in An American City", Chicago: The University of Chicago Press}

Pedro Saraiva

\section{OpenEdition}

\section{Journals}

Edição electrónica

URL: http://journals.openedition.org/configuracoes/7824

DOI: $10.4000 /$ configuracoes.7824

ISSN: 2182-7419

Editora

Centro de Investigação em Ciências Sociais

Edição impressa

Paginação: 126-129

ISSN: 1646-5075

\section{Refêrencia eletrónica}

Pedro Saraiva, «Alice Goffman (2014), "On The Run: Fugitive Life in An American City", Chicago: The

University of Chicago Press », Configurações [Online], 24 | 2019, posto online no dia 18 dezembro 2019, consultado o 24 setembro 2020. URL : http://journals.openedition.org/configuracoes/7824 ; DOI :

https://doi.org/10.4000/configuracoes.7824 
Saraiva, Pedro - Alice Goffman (2014), On The Run: Fugitive Life in An American City. Configurações, vol. 24, 2019, pp. 126-129.

\section{Alice Goffman (2014), “On The Run: Fugitive Life in An American City", Chicago: The University of Chicago Press}

PEDRO SARAIVA*

Centro de Estudos Sociais - Faculdade de Economia da Universidade de Coimbra

Existem várias formas de fazer investigação sobre um determinado objeto de estudo. Tal como existem várias formas de estudar esse mesmo objeto, através de várias técnicas metodológicas. Mas, e quando o próprio investigador se envolve com esse objeto de estudo, fazendo parte dele mesmo? Esta é a relação que Alice Goffman desenvolve com o seu objeto de estudo, a comunidade negra do 6th Street em Filadélfia, nos Estados Unidos da América.

Através de uma etnografia feita com observação participante, no qual a autora conheceu várias pessoas deste bairro, tendo mesmo entrado nas suas vidas particulares. Tal como estas pessoas, também experienciou as formas de vida nesta comunidade, tendo mesmo assistido à morte de uma pessoa, com um tiro na cabeça e chegou mesmo a ser detida para interrogatório policial, de forma a denunciar algumas das pessoas que conhecia, detida e deitada ao chão durante revistas às casas das pessoas que conhecia e onde estava de momento.

Estes são alguns exemplos de momentos vividos pela investigadora que agora publica no livro On The Run: Fugitive Life in An American City (2014), onde relata a sua experiência de ter vivido nesta comunidade durante 18 meses e onde percebeu o que era ser negro e a relação desenvolvida com o sistema penal, através dos seus instrumentos de ação (polícia, tribunais, prisões e centros juvenis de detenção).

\footnotetext{
* Estudante de Doutoramento em Sociologia - Faculdade de Economia da Universidade de Coimbra. Email: pdgs@outlook.pt
} 
$\mathrm{Na}$ introdução, Goffman começa por explicar que a par da introdução de direitos civis a partir dos Anos 60, que equipararam os afro-americanos aos restantes cidadãos brancos norte-americanos, também se verificou uma transformação de todo o sistema penal e dos seus instrumentos de ação (desde a formação de polícias ao agravamento das penas já existentes). Como resultado disto, e devido às desigualdades de acesso à educação, uma larga percentagem de negros, de classes baixas, acabam por ter um percurso de vida relacionado com o sistema penal, tendo já estado presos ou com familiares presos. Focando a atenção no 6th Street, bairro constituído sobretudo por negros de baixos rendimentos, a autora fez uma observação participante, com observações quase diárias durante 18 meses, sobre a relação que é desenvolvida entre os habitantes e a polícia que garante a segurança nesta comunidade.

No capítulo 1 (The 6th Street Boys and Their Legal Entanglements), a autora apresenta-nos alguns casos de jovens que, com circunstâncias diferentes de vida, entraram com tenra idade, no mundo da droga, tendo-se tornado vendedores da mesma, e, desde muito cedo, começaram a ser presos por isso mesmo, desenvolvendo uma relação com a polícia e com o sistema penal. Essa relação materializa-se no medo de ser apanhado e de ser preso e mesmo depois de saírem, têm medo de fazer determinadas ações, como sair à noite ou visitar amigos, com medo de voltarem para a prisão ou para os centros juvenis de detenção. Isto demonstra também um sistema sofisticado que a polícia criou e que é aperfeiçoado ao longo do tempo, para combater o tráfico de droga e meter ordem no bairro.

No capítulo seguinte (The Art of Running), é apresentado ao leitor, as várias estratégias que estes jovens, que são introduzidos no primeiro capítulo, usam para fugir da polícia e de uma eventual detenção. Com medo de serem detidos, vários locais públicos são evitados, como por exemplo, os hospitais, cemitérios ou espaços de serviços públicos. Desenvolvem um sentido apurado para detetar polícias à paisana e evitam as casas de familiares, uma vez que sabem que podem ser procurados nestes locais. Desconfiam de familiares, de amigos e de vizinhos, pois têm receio que estes os denunciem. Como forma de tentar aliviar as penas que têm de cumprir, acabam por denunciar amigos, criando conflitos entre amigos de longa data.

No capítulo 3 (When the Police Knock Your Door In), são apresentados através de vários exemplos de como as pessoas mais próximas dos detidos, sobretudo quando são do sexo feminino (namoradas, esposas, mães), são alvo de técnicas de persuasão por parte da polícia. Sendo ameaçadas de que serão presas por vários crimes, que perderão a custódia dos seus filhos ou as casas onde habitam, estas mulheres são pressionadas para colaborarem e entregarem estes homens. Decisões que são difíceis, porque sabem que terão influência nas suas relações futuras com estes detidos, assim como atingem a sua própria autoestima (veem-se como sendo traidoras da confiança destes detidos). 
No breve capítulo 4 (Turning Legal Troubles into Personal Resources), a autora mostra como a relação entre estes detidos e pessoas próximas com o sistema penal pode servir interesses, tanto de detidos, como destas pessoas próximas. Por um lado, se houver conflitos entre gangues, estes detidos fazem o que podem para irem para a prisão (por exemplo, violam a liberdade condicional), para, dessa forma, se sentirem mais seguros. Mas por outro lado, como forma de obrigar estas pessoas a mudarem de vida ou por interesses pessoais, estas pessoas mais próximas/mais íntimas usam o medo dos detidos de serem presos de modo a conseguirem o que pretendem (por exemplo, estarem mais tempo em casa).

No capítulo seguinte (The Social Life of Criminalized Young People), usando alguns exemplos vividos pela autora, é possível perceber que além destes jovens criarem uma relação com o sistema penal, desde muito jovens, não são apenas estes que estão envolvidos nesta relação. São todas as pessoas que pertencem ao seu círculo próximo (mães, namoradas, amigos, vizinhos), que os visitam às prisões e aos centros de detenção juvenil.

No penúltimo capítulo (The Market in Protections and Privileges), percebe-se que não são só os detidos e as pessoas próximas deles que estão envolvidos com o sistema penal. Existe igualmente um sub-mundo composto por várias pessoas que dão assistência a estas pessoas. Por um lado, existem negócios ilegais que garantem assistência médica, sem recorrer aos hospitais, evitando o risco de se serem identificados e detidos ou, também, correios de droga, que, ao visitar familiares nas prisões, levam drogas para serem consumidas dentro das prisões. Por outro lado, os funcionários deste sistema penal (guardas e funcionários judiciais), desenvolvem os seus próprios negócios ilegais (venda de telemóveis, tabaco ou droga para consumo interno por parte dos guardas prisionais).

Por fim e antes das conclusões gerais da autora, no capítulo 7 (Clean People), e apesar dos vários casos de pessoas negras que são detidas e que desenvolvem uma relação com o sistema penal, desde muito jovens, existem pessoas que vivem neste mesmo bairro e que conseguem superar as dificuldades encontradas, procurando uma vida melhor. São apontadas algumas pessoas que conseguiram terminar o ensino secundário e chegaram mesmo a ir para a universidade. No entanto, devido às ligações a pessoas que estão inseridas no mundo da criminalidade e como forma de os ajudar, acabam por se prejudicar, como, por exemplo, perdendo o emprego. No entanto, com maiores ou menores dificuldades, conseguem gerir a relação com os atores sociais que se encontram nesta comunidade e as suas próprias vidas, que desenvolvem fora desta comunidade.

Numa conclusão geral, a autora reitera que apesar de se ter avançado em relação aos direitos dos cidadãos afro-americanos ao longo das últimas décadas, verifica-se uma contínua violação dos direitos destas pessoas, na sua 
grande maioria pobres, com o sistema penal, através dos seus sistemas de ação a terem um grande controlo sobre a vida destas pessoas.

Numa avaliação a este livro, percebe-se o porquê de ter sido aceite para publicação. Este deveria ser um livro de leitura obrigatória para qualquer académico ligado à área da Sociologia, por duas razões essenciais. Por um lado, pelo seu conteúdo, mas por outro lado, pela forma como a investigação foi feita.

Se pensarmos no seu conteúdo, a experiência de Alice Goffman nesta comunidade evidencia que, apesar do avanço nos direitos civis dos negros, existe uma clara violação desses mesmos direitos, com estes cidadãos a serem tratados como cidadãos de $2^{a}$ categoria, em relação aos cidadãos brancos, pela polícia e pelos tribunais norte-americanos. Muito tem sido feito nos EUA para inverter esta tendência, mas é necessário muito mais. Sobretudo, é necessário combater situações de desigualdade, evidentes em áreas como a educação, a saúde ou no acesso ao mercado de trabalho. Áreas fulcrais para que estas pessoas não caiam no mundo do crime e consequente relação com o sistema penal

Se pensarmos na forma como a investigação foi feita, nomeadamente em termos metodológicos, este é um excelente exemplo de como é feita uma etnografia participante, e apesar de não especificar como foi feita nestes capítulos (apenas explica no appendix), houve todo um trabalho de chegar ao terreno e de negociar o seu espaço nesta comunidade. Além disso, mostra claramente como por vezes o critério de "saturação", não é o único critério que influencia uma investigação. São vários os fatores, nomeadamente externos, como por exemplo, o financiamento disponível para a investigação que é sempre limitado. Mostra igualmente, que ao contrário do que como a ciência é feita hoje (fast science), é possível fazer investigação de uma forma mais calma (slow science), adquirindo mais dados a serem analisados.

Um livro sobre os nossos tempos, que nos obriga a refletir, sobre o que é ser negro numa comunidade pobre de uma das grandes cidades dos EUA, mas que também nos obriga, enquanto investigadores e académicos, a refletir sobre como deveremos fazer investigação nos nossos próprios projetos sociológicos. 